\title{
FIRE CONTROL PLANNING ${ }^{1}$
}

\author{
By A. E. SPAULDING ${ }^{2}$
}

A. E. Spaulding is a native of Montana. He has been associated with forest fire control activities for 30 years. Having worked seasonally during his school years in the fire organizations of the U.S. Forest Service, Blackfoot Forest Protective Association, and in the mill and woods operation of the Anaconda Company, he decided that forestry was the career for him. After obtaining a B.S. degree in Forestry at the University of Montana, he was employed by the U.S. Forest Service; later he was in northern Idaho and north-eastern Washington as district forest ranger, assistant supervisor, and forest supervisor. He is assistant regional forester in charge of the Division of Fire Control, Northern Region, U.S. Forest Service, Missoula, Montana.

I am glad to have this opportunity to discuss fire control planning with you. The invitation from Mr. Marshall to appear on your program was readily accepted. The insignia on his stationery informed me that 1955 was Saskatchewan's Golden Jubilee.

This year of 1955 is also the Golden Anniversary of the United States Forest Service. Fifty years ago the Forest Service was created in its present form in the Department of Agriculture. Although forestry in the United States received' attention as early as 1876 , it was not until the present Forest Service came into being that a rounded national policy for forestry was developed. Work then began to go forward with long-range objectives to maintain and increase the productivity of forest lands everywhere in the States. Working together, private and public agencies have made good progress in forestry during the last half century. We have effectively demonstrated the values of organized protection against fire, insects, and disease, and of good management and wise use of the Nation's forest resources.

Most of my forestry experience has been in the Northern Region of the U.S. Forest Service. In discussing fire control planning with you, my remarks will be directed at problems we have encountered in providing fire protection to some 33 million acres in Montana, northern Idaho, and northeastern Washington.

To illustrate our progress in fire control, I will divide the last half century into three periods that denote major milestones in fire control planning.

1. During the 1905-1930 period our annual average burned area was 252,000 acres. Thus for the first quarter century, forest fires greatly damaged more than 6 million acres. During this devastation the forest was inaccessible and travel was by foot or horse. Fire control planners had long recognized the critical need to speed up attack on fires.

\footnotetext{
${ }^{1}$ Paper presented at the 1955 Annual Meeting of Canadian Institute of Forestry at Saskatoon, Sask.

${ }^{2}$ Assistant Regional Forester in charge of the Division of Fire Control Northern Region, U.S. Forest Service Missoula, Montana.
} 
2. During the 1931-1940 period, roads into many areas speeded up travel time to 15 miles per hour and the average annual burned area was reduced to 62,500 acres. This was double the destruction that we could afford if we were to meet our objective of managing the area for sustained crops. During this period, analyses proved that much of the excessive burned area was occurring in the remaining roadless areas. Some of these were dedicated to remain roadless and others were not developed due to lack of funds or high cost of road construction. Increased use of airplanes to speed up delivery of supplies during this period logically led to the delivery of fire fighters by parachute.

3. During the 1941-1955 period, the growth of aerial fire control along with the use of smokejumpers speeded travel time to fires in remote areas and assisted in reducing the average annual burn to 8,000 acres.

With only these facts available, we might conclude that for this area the fire control manager has successfully met or bettered his objective and that no additional fire control planning is necessary. Such an assumption would be far from the truth if all the facts are known. A lot of good planning and a lot of good work contributed to the reduction in burned area. During the last 15 years, weather has also been more favorable than during the late 1920's and early 1930's. Smokejumpers in combination with the ground forces and other improved methods have in recent years kept fire losses and damages at a lower level. During the more severe fire years, available facilities are insufficient to man all fires soon enough and during such periods damaging and costly fires can still occur. This is a challenge to fire control planners.

Developments such as the helicopter, as it is improved and becomes available with larger capacity and operational ability at higher elevations; research findings in fire-danger measurements, knowledge and control of weather factors; and technological developments such as radar for detection; and improved fireline-building machines and other projects, will all receive consideration by the fire control planner to assist in solving this problem.

In the Northern Region of the Forest Service we are using the old methods as well as the new. Men still have to walk across country with packs on their backs; mules carry supplies and equipment over the trail system; travel and hauling by vehicles on roads is an essential part of fire control; pumps, tankers, and available fire-trench-building machines are used; smokejumping has become routine on wilderness-area fires; small helicopters are regularly used-in short, a combination of the old and newer methods of fire fighting is used that best meets the conditions at hand.

During the last half century, we have planned and re-planned for adequate fire control. A fire plan must be a living thing, subject to change, and I expect that we will go right on revising our plans as we strive to do a more efficient job.

\section{Definition of Fire Control Planning}

Planning for fire control on wild lands presents a different picture to different men. To me it is the determination of an acceptable objective along with the determination of all the measures needed to meet that objective. This 
is a broad concept of the subject. I believe we must so treat it to prevent an analysis and plan for only one or several of the many facets of fire control from being called a complete fire plan.

In the design of fire plans we usually attempt to provide for average worst conditions, recognizing that a normal plan will not cover the worst fire periods. This is similar to the principles an engineer follows in designing a bridge that will meet needs with a reasonable margin but may not handle the worst flood or greatest possible overload. The plan should, however, go as far as possible in meeting the worst conditions on an emergency basis.

\section{ObJective}

The over-all objective of the United States Forest Service in the fire protection of national forests is to hold fire damage below the level at which it would seriously interfere with the desired yield of products and services from forest land, and to prevent other serious adverse effects of forest fires, among which are such effects as those of public health, safety, or convenience-and to do the job at least cost. This is a broad objective and not sufficiently tangible to provide a foundation for plans of action.

Objectives for fire control are and have been a controversial topic. The theory of least cost plus damage has many supporters. An objective expressed in allowable annual burn has long been used for forest types, such as $2 / 10$ ths of 1 percent, or $1 / 10$ th of 1 percent. This objective, when applied to a large area, could mean the total allowable damage for any one year might occur in one local unit, causing untold damage and suffering to a dependent community. We are now making progress in setting up allowable burned area by management units in accordance with values and fire potential involved. When this has been done, the fire control planner can proceed to make an action plan to meet this objective.

In some cases the owners of forest property may have a fixed sum they will spend on fire control. If this sum is insufficient for adequate fire protection and cannot be increased, the fire control planner's job is to provide the best possible protection within the prescribed limits. With a rapidly increasing population, forest resources are becoming more valuable and experience has proved that it is good business for owners to buy good fire protection. The fire planner has a responsibility to inform the owner of the amount of insurance he is carrying on his property.

Many foresters believe that determination of an acceptable objective is a function of the resource manager or owner and not the fire planner. I placed additional responsibility on the fire control planner in my definition to emphasize the need for an acceptable objective as a foundation for planning and that he will need to get concurrence on an objective to do his job properly.

Following a review of the fire history and potential of an area along with values involved and the determination of an acceptable objective, the fire control planner should sufficiently understand the economics of the situation and be in a position to establish some balance between the three major divisions of fire control, namely, prevention, presuppression and suppression.

I shall discuss each of these major subjects separately. 


\section{FIRE PREVENTION PLANS}

A fire prevention plan, if needed, should be based on the following minimum analysis:

\section{a. Study of risks.}

1. An analysis of man-caused fires by causes for previous 5 years to determine specific reasons why fires start and who starts them.

2. Location of man-caused fires by causes for same 5-year period.

3. Location of areas of special risks, i.e., railroads, sawmills, woods operations, power lines, construction crews, towns, etc.

4. Dates when man-caused fires start.

\section{b. Study of areas of special hazards.}

Location of areas of special hazards, such as slash areas, blow-downs, fire- and insect-killed timber, etc., and careful identification and survey of local hazards in special-risk areas.

\section{c. Correlation of all hazard areas with the risk factors.}

This is to provide a clear over-all picture of the fire-starting and/or spreading potential, to identify the areas and periods of special fire liability, and to facilitate the setting up of priorities.

\section{General Principles in Development of Action Plans}

Fire prevention planning, which concerns itself with the problem of reducing total costs and damage, must recognize fire risks, forest fuels, and other fire hazards, as critical factors in undertaking remedial action.

The time of day, year, place, and the number of fires that start, usually control the size of the fire organization that must be maintained, and are decisive, too, in the fire-fighting costs and damage that result.

Where these things depend on the exposure of critical fuels to human risks, attainment of the whole objective requires the kind of management that will remove or reduce the risk or the fuel hazard, or that will minimize the potentials of one or both.

\section{OBJective}

The objective of fire prevention is to eliminate preventable fires. Final attainment of such an objective is necessarily limited by many factors, but levels of attainment far short of this goal are not regarded as acceptable unless the additional cost of improved performance will clearly exceed the benefits gained in reduced losses and suppression costs.

\section{ACtion Plan}

Following consideration of the above factors, an action plan will be developed for each unit. This action plan specifically sets forth what shall be done, where it shall be done, when it shall be done, and who shall do it, with provision for recording degree of accomplishment.

The action plan is an annual work plan and should be made each year as changes in responsibility assignments are usually made from year to year. 
The analyses that proceed the preparation of the action plan should be made once every five years, as a minimum, and oftener when material changes occur in the risks involved.

\section{PRESUPPRESSION PLAN}

The basic elements involved in presuppression planning are:

a. Meteorological factors including wind, relative humidity, fuel moisture, precipitation, seasonal effects, etc.

b. Topographic factors relating to configuration of the country, such as ridges, slopes, streams, canyons, draws, etc., and the relative location of one to the other, elevation, steepness, soil conditions, barriers, etc.

c. Fuel factors including (1) types of fuels such as mature timber, second growth, slashings, brush, grass, forest litter, down logs, snags, etc., (2) continuity, density, and arrangement of fuels, (3) their resistance to line construction.

d. Occurrence dealing with incidence of fires as to points of origin, intensity of occurrence identified separately for lightning and each man-caused category, times of day and year fires may be expected to start and do damage.

e. Visibility as it applies to distance incipient small forest fires may be seen by detectors; normal daily or seasonal changes in visibility distance, etc.

f. Accessibility. Availability or non-availability of roads, trails, ways, fire lanes, bridges, airstrips, lakes or rivers for airplane landings, helicopter landing spots, etc., and the travel time, by the most appropriate means, required to reach areas of fire occurrence.

g. Relative values (tangible plus intangible) at stake are one of the considerations in deciding the placement or intensity of the pre-suppression organization.

h. Rate of production of held line per unit of manpower or machines for different conditions, including delineation of areas where machinery is usable.

i. Water supply for suppression as related to portable pumper chances or tanker-filling facilities.

j. Equipment. Trucks and pickups, trailbuilders, tankers, aircraft, tools and related equipment for fireline work, and other facilitating gear.

k. Communication. Radio or telephone, or in combination, for presup-. pression and suppression.

While not strictly a basic element of planning, the need for providing plans for recruitment of suitable personnel to fill each planned fire position, including co-operators and their subsequent training to do the job efficiently and safely, must be recognized in order to carry out the master presuppression plan. Provision must be made also for recruitment and on-the-job training of able-bodied emergency fire forces. 


\section{OBJectrve}

Objective of the presuppression plan shall be to have available, when and where needed, an effective fire control organization, well trained, equipped, instructed and supervised, and capable of handling efficiently the fire suppression situations which sound planning determines to be necessary.

\section{Master Presuppression Plan}

In the development of a presuppression plan for each area, all of the basic elements mentioned above must be thoroughly considered as to their effect on that unit. The master presuppression plan is a term applied to a grouping of the following plans dealing with the detection and preparedness phases of the fire control job:

\section{a. Detection}

Detection involves consideration of visibility distance; zones of occurrence of fires as indicated by past history, and changes in risk areas due to changing use; maps showing extent of area seen from individual points; selection of points by process of statistical elimination; final map showing seen and unseen area from all selected points; establishment of dates of occupancy and provision for regulation of occupancy in accordance with measured fire danger; incorporation of aerial detection-either primary or secondary.

\section{b. Initial Attack}

Initial attack usually involves mapping of fuels to show combined effect of rates of spread and resistance to control; occurrence of fires by intensity zones; accessibility; initial-attack strength by zones required for varying degrees of fire danger; location of crews to meet travel-time requirements; provision for varying strength of crews in accordance with measured fire danger, to meet initial-attack requirements for each zone; establishment of dates of employment, and recognition of the need for reinforcements.

In the Northern Region of the U.S. Forest Service, we have made major changes in our detection and initial-attack plans. During the early 1930's we intensively mapped fuel types, determined hour-control requirements, and ground detector needs. As a result we constructed approximately 800 lookout houses. Men hired for these stations had a dual capacity as lookout-firemen and other firemen were placed in valley bottoms when needed to complete the hourcontrol coverage. This system was successful as long as we could hire the number of men needed; men who were rugged woodsmen, capable of finding a fire and putting it out and were willing to live alone all season. Under our current economic conditions such men are not available in sufficient numbers at the salary we can pay and for only a seasonal job.

This placement of men did not provide for needed flexibility in moving men rapidly to another location where more than two or three men were needed for early attack on a difficult small fire. We also found that the comparatively few firemen stationed in the valley bottoms, particularly those on roads, became the initial-attack force on a majority of the fires. 
The 800 lookout towers were constructed from untreated native woods obtained close to the site and after 20 years they all began to deteriorate rapidly and many became unsafe for use. In addition we gradually became financially unable to maintain trails and telephone lines to all of these stations. As a result we gradually changed our plan by moving some of the lookoutfiremen to double-up fireman positions in the valley bottoms.

In the early 1940 's, many of these fireman positions in the roadless areas were abandoned and were replaced by a centralized smokejumper unit. Because of their flexibility, they have replaced twice their number of firemen. Two or more smokejumpers can now get to a fire as quickly as one fireman did when we had many of the latter strategically placed in the roadless areas. Where we used to get one man to a fire within one hour, but to get 20 thére might take 2 days, we can now put 20 smokejumpers on the fire within one hour when the situation warrants. This is where flexibility pays off. There are times when the number of smokejumpers is insufficient to meet the need. We then resort to use of helicopters as far as they are available and can be used, and then must rely on slow foot travel to meet the remainder of the need. I might well mention here that smokejumping has great public appeal and in our area receives 90 percent of the fire control publicity. Actually smokejumping takes care of less than 20 percent of our fires with the remainder being handled by older conventional methods.

Our detection system has also been overhauled in recent years. We now have a skeleton force of about 200 lookouts who are primary detectors covering the high-risk areas. They are important in charting the course of lightning storms, precipitation, in making burning index measurements, and in serving as radio communication hubs. Planned aerial detection fills in most of the gaps left in the reduction from 800 to 200 fixed detectors. Flexibility gained here is also important as it costs little to leave the airplane on the landing strip when this additional detection is not needed. With fixed detectors only, we had little flexibility as a station in a remote area could not be occupied only on the days needed and the man not be paid on other days.

Getting back to other requirements of the fire plan, we have:

\section{c. Equipment}

1. Small tools. Determination of types and quantities of tools for each initial attack and co-operator station; also, determination of small-tool and equipment requirements for regional, forest, and district warehouses for follow-up forces.

2. Transportation equipment. Study of transportation needs of each initialattack station, ranger's and supervisor's headquarters.

3. Specialized equipment. Determination of types, quantities and locations of tank trucks, prime movers, plow units, trailbuilders, portable pumpers, aircraft, and other specialized equipment; involves the types and quantities of specialized equipment required for initial attack, forest and ranger stations, and regional or zone central caches. 


\section{d. Communication}

Communication-radio and/or telephone. These include:

1. Detection. Plan providing communication outlets for detectors-must provide immediate channels for detectors to report fires to dispatching base.

2. Initial attack. Provision must be made for immediate communication between dispatching base and initial-attack crews whether co-operators or employed by Forest Service.

3. Dispatching base. Must provide immediate communication outlets from dispatching base to all detectors, initial-attack crews, follow-up forces such as work crews and co-operators, and to forest and ranger headquarters.

4. Suppression. A plan must be made which will provide communication both from the fireline to the camp or to other sections of the fire, and from the camp to the dispatching base; numbers and types of radio, emergency phones, or other communication facilities required for these purposes must be determined. Communication between initial-attack crews when away from their stations and the dispatching base must likewise be provided wherever possible and made a part of this plan.

\section{e. Co-operators}

Determination of the extent to which co-operators may be incorporated into the presuppression phases of fire control. In many cases co-operators may be used in the initial-attack field, releasing funds for other areas where co-operators are not available.

\section{f. Training.}

A training plan must be prepared, listing the minimum training needs of each presuppression position-lookouts, suppression crew foremen, crew members, tank-truck operators, patrolmen, packers, tractor operators, fire control assistants, and others who may be assigned full time or temporarily to fire control work of any kind. Provision should be made to maintain a current record of progress made in training each individual. This plan should require an annual analysis of each incumbent's experience and training prior to entry on duty, to determine what he or she needs to learn to qualify for the position and to effectively and safety handle the assigned tasks.

\section{g. Dispatching}

Annually, a dispatching plan, sometimes termed "emergency fire plan," should be prepared, providing information on the location, strength, and provisions for contacting and mobilizing the following, with the purpose of providing adequate forces to meet the Service suppression policy:

1. All initial-attack stations-Forest Service or co-operator.

2. All Forest Service work crews.

3. All private work crews, i.e., logging, mill workers, railroad, power companies, orchard workers, etc. 
4. Initial-attack forces of co-operating protection agencies.

5. Follow-up forces or facilities of co-operating protection agencies.

6. Forces of adjacent national forests.

7. Pick-up fire fighters.

8. Overhead, segregated as to skills from which fire overhead teams may be selected, or from which assignments to individual fire suppression jobs may be made.

9. Cooks, packers, power-saw operators, trailbuilder operators, and others having specialized skills.

10. Tools and equipment, including transportation equipment, trail-builders, tank trucks, etc.

11. Food, mess equipment, first aid, and other supplies and materials.

12. Communication equipment, including emergency wire, field telephones and radios.

13. Special detectors.

Also the dispatching plan should include ways and means and authority for varying the disposition or strength of the presuppression force in accordance with measured fire danger.

\section{h. Housing}

Because of its importance, a housing plan should be incorporated in the master presuppression plan which should indicate the housing facilities required to effectuate the plan and the housing facilities available. Changing patterns of use or fuel conditions should be given full recognition and weight in deciding whether to provide portable, semi-portable, or permanent housing facilities, in order to permit ready shifting of forces to meet changed conditions.

\section{i. Recruitment}

A recruitment plan must be prepared and revised annually to provide the best possible (1) presuppression force, (2) force for use in fire emergencies.

\section{j. Transportation}

Plan usually outlines diagrammatically on map or maps the location and standards of all roads, trails, bridges, air strips, and helicopter landing spots needed to meet the elapsed-time standards for the area; primary consideration is to provide accessibility for initial-attack and follow-up forces.

\section{FIRE SUPPRESSION PLANS}

Fire suppression plans separate and apart from the presuppression plan are not normally made by us in advance of the actual fire. Most material that would logically belong in a fire suppression plan has already been included above under the heading of presuppression plans. However, we do have a number of situations where an especially high fire hazard may require the making of a special fire-fighting plan in advance of fire occurrence. Such a plan is helpful to the fire boss once the fire escapes control of the first-burning- 
period attack force. They cannot always be followed but the detailed map of fuels, topography, cover type, roads, water chances, etc., provide an excellent basis for revising the plan to meet conditions immediately at hand.

\section{Policy}

Our policy is to require fast, energetic, and thorough suppression of all fires. When first-attack forces fail to attain this, the policy then calls for prompt calculating of the problems of the existing situation and probabilities of spread; and organizing and activating adequate strength to control every such fire within the first work period. Failing in this effort, the attack each succeeding day will be planned and executed with the aim of obtaining control before 10 o'clock of the next morning.

\section{Calculation of Probabilities}

Probably a better term for calculation of probabilities is an estimate of the job we must do to control the fire. Controlling a fire can be compared to building a road or a bridge. The fire boss needs a plan based on the job he will have to do. This includes evaluation and correlation of the factors affecting fire behavior, knowledge of the probable perimeter of the fire at successive time intervals and the expected number of units of held line per unit of manpower or applicable machine unit or both, to determine the organization-including overhead, manpower, and equipment he will need. The fire suppression plan of action is then prepared day-by-day to meet actual conditions and revised at shorter intervals when the situation warrants

\section{Actuarial Planning}

Some authorities on fire control planning do not agree with the subject divisions used above in this presentation. Ralph Hand, who recently retired after 15 years in the fire planning job in Missoula, divided the subject into prevention, detection, and suppression. I believe that this has merit and should be considered when preparing for a job in fire control planning. Ralph Hand also developed a system based on actuarial principles for suppression planning that is interesting and highly successful. Briefly, this system provided a series of actuarial tables based on an analysis of 20 fire seasons and 27,000 fires. Each fire was re-fought on the basis of present-day conditions of transportation, fuels, and methods. In these tables we had the facts that would give us answers to almost any specfiic question in the field of fire control planning. They were particularly valuable in:

1. Determination of basic needs, such as manpower, machines, and equipment.

2. Determination of facilitating needs such as transportation, communication, supervision and training.

3. Preparing the action plan.

4. Providing the facts to indicate the amount or level of fire insurance that was being carried on a forest property.

This subject of fire planning by actuarial principles to explain fully would take an entire day; however, I would like to recommend that these 
principles be investigated before re-planning is started where fire records are available for the area for the preceeding decade or a longer period.

\section{SUMMARY}

To finish this paper and open the discussion period, I would like to state that this is far from a complete coverage of the subject. I have borrowed much of my text from our National Forest Manual and make no claim for originality. In closing, I'd like to again emphasize that a fire plan must be a living thing, frequently modernized, to be most useful.

\section{DISCUSSION}

\section{Following Papers by J. C. Macleod and A. E. Spaulding}

\section{E. Williams:}

Are fuel type maps made up from forest type maps or do they make a special survey for a fuel type map?

\section{A. E. Spaulding:}

Back around 1932, '33 and '34 we put on a special project of fuel type mapping. We had one man per ranger district (about 200,000 acres). These men spent the whole summer preparing fuel type maps. We hoped that we could keep them up to date but we have not been able to do so. We have been able to keep track of the undisposed slash areas, and have showed a lower hazard when disposal of the slash has been completed. One of our weak points right now is that our fuel type maps are not up to date, nor have we the money to do anything about it at present.

\section{G. Tunstell:}

Mr. Spaulding was speaking about the switch over from towers to aircraft and the reason for this change. Supposing now that you should find yourself with ample man power available. Would you switch back to towers?

\section{A. E. Spaulding:}

There are quite a few reasons why we switched from look-outs. Many of the look-outs were placed where they were because they had to be there to meet the hour requirements of fire control. We had to have a smoke-chaser there to get to areas of high hazard in the required time. During the depression you could get excellent men to do fire ranging summertime jobs, but it is difficult to do today. The cost of towers has increased from about $\$ 1,800$ to $\$ 7,000$ $\$ 10,000$. I don't think we'll be going back to more towers, but I would like to have more smoke jumpers or more fire rangers at strategically located stations.

\section{S. W. Schortinghuis:}

I wonder if you could tell those of us who are just beginning in the field of fire control planning, what costs we might expect?

\section{A. E. Spaulding:}

We had a really tough fire year two years ago. On thirty million acres we spent $15 \mathrm{c}$ an acre, which was our highest cost on record. About two-thirds of this cost was fire fighting. Our prevention and preparedness cost in our heavy 
fuel types runs up to $8 \mathrm{c}$ per acre. East of the Rockies it is about $3 \mathrm{c}$ per acre. Our average annual suppression costs would be about $4 \mathrm{c}$ for the west and $2 \mathrm{c}$ for the east side.

\section{R. G. Steele:}

Our conditions in Alberta from 1941 to 1950 have been almost identical to yours from 1905 to 1930 . We have about three times the area to protect that you have and our average annual burn has been about 800,000 acres per year compared to your 252,000 . Our objective right now is to reduce our burn from 0.85 per cent per year to about 0.25 per cent per year which is comparable to your period of 1941 to 1950 . We only hope that we can set up a program that will reduce our burn as rapidly as you have in the last 25 years.

\section{G. A. Kingston:}

In the classification of your fuel types are there actual measurements made of how hot the fires burn and how fast they travel?

\section{A. E. Spaulding:}

Yes, we made some actual tests. One of our men did a lot of work in this connection on small and large fires, and on brush disposal fires which were carried out in high hazard periods. The same study also included resistance to control. These studies were done before the days of bulldozer use on fire lines, so our information here is a little out of date. We have a lot of statistical information from our own fire reports. 